\title{
Potential Medicinal and Nutritional Resources from the Sericultural Industry
}

\author{
Yu-Xiao Zou*, Sen-Tai Liao, Fan Liu, Wei-Zhi Shen, Jun Liu, Ying Shi and Li-Xia Mu
}

Sericultural \& Agri-Food Research Institute, Guangdong Academy of Agricultural Sciences, Guangzhou, P.R. China

\begin{abstract}
Sericulture is a traditional and well-known industry with a 5000-year history in China. 'Byproducts of sericulture' which do not directly generate economic benefits, are typically wasted: e.g., fruits, stems, surplus leaves from silkworm feeding, pupae and moths. However, the above resource is of great potential nutritional and medicinal value and deserves systematic and profound study.
\end{abstract}

Keywords: Sericultural products; Medicinal value; Nutritional value

\section{Introduction}

Sericulture is a traditional and well-known industry with a 5000year history in China. China ranks first in the world with respect to silk production, with over three-quarters of global silk originating from this country. Mulberry trees have been traditionally cultivated for their leaves, which provide food for silkworms. Sericultural farmers make money from their cocoons by traditional management practices [1] and the 'byproducts of sericulture', which do not directly generate economic benefits, are typically wasted: e.g., fruits, stems, surplus leaves from silkworm feeding, pupae and moths. Although many medicinal benefits of sericultural byproducts are recorded in ancient Chinese materia medica, the potential nutritional and medicinal value of sericultural resources received little attention until 1-deoxynojirimycin (DNJ), a naturally occurring alkaloid with powerful $\alpha$-glucosidase inhibitory activity, was isolated from mulberry trees in 1976 [2].

\section{Nutritional and Medicinal Value of Mulberries and Mulberry Leaves}

Mulberry trees grow in a wide range of climatic, topographical and soil conditions and are widely distributed, from temperate to subtropical regions of the Northern hemisphere to the tropics of the Southern hemisphere [3]. The reasons for planting mulberry trees differ between Asian and European countries. In China and India, the foliage of the mulberry is used to feed silkworms. However, in many European countries, particularly Turkey and Greece, mulberries are grown for fruit rather than for their foliage [4].

Mulberries are nutritious fruits, rich in ascorbic acid (19.4-22.4 $\mathrm{mg} / 100 \mathrm{~g}$ ), total soluble solids (15.9-20.4\%), and minerals (1141 mg/100 $\mathrm{g} \mathrm{K}, 139 \mathrm{mg} / 100 \mathrm{~g} \mathrm{Ca}, 109 \mathrm{mg} / 100 \mathrm{~g} \mathrm{Mg}, 60 \mathrm{mg} / 100 \mathrm{~g} \mathrm{Na}, 4.3 \mathrm{mg} / 100 \mathrm{~g}$ $\mathrm{Fe}$, and $3.1 \mathrm{mg} / 100 \mathrm{~g} \mathrm{Zn}$ ) [5]. Furthermore, in recent decades, mulberries have been recognized as a beneficial food with several health-promoting effects attributed to phenolic compounds and polyhydroxylated piperidine alkaloids. The phenolics in mulberries consist of flavonoids, anthocyanins and carotenoids. Mulberry anthocyanins mostly consist of cyanidin-3-glucoside (79\%) and cyanidin-3-rutinoside (19\%) [6] but other phenolics, including the powerful antioxidants resveratrol, oxyresveratrol, rutin, quercetin, and kaempferol-3-rutinoside, are also present [7-8]. Additionally, mulberries are rich in iminosugars, such as the glucose analog 1-deoxynojirimycin (DNJ), which is currently generating intense interest because of its high potency as a glycosidase inhibitor.

Mulberry leaves are also considered an excellent source of protein, minerals and dietary fiber [9]. Like mulberry fruits, they contain many bioactive compounds, such as flavonoids and polyhydroxylated alkaloids but their phytochemical profiles are quite different. Besides DNJ, mulberry leaves are rich in other iminosugars, including 2-O- $\alpha-$ D-galactopyranosyl-deoxynojirimycin, 4-O- $\beta$-D-glucopyranosyl-1deoxynojirimycin, calystegine B2, fagomine [10]. Mulberry leaves are also particularly rich in chlorogenic acid, benzoic acid, rutin and astragalin.

Both mulberries and mulberry leaves have been used as medicines and nutritional foods. Mulberry phenolics and polyhydroxylated alkaloids possess a wide spectrum of biochemical properties, including hypoglycemic [11], antioxidant [12], anti-inflammatory, hepatoprotective [13], and antitumor activities [14]. Mulberries and mulberry leaves are considered excellent dietary supplements to ameliorate chronic diseases [15].

\section{Nutritional and Medicinal Value of Silkworm Pupae and Moths}

The silkworm is a holometabolic insect, passing through the developmental stages of egg, larva, and pupa to the adult moth. Silkworms are oligophagous insects, feeding exclusively on mulberry leaves at the larval stage and converting leaf protein into silk protein. The larvae simultaneously absorb and accumulate bioactive compounds from the leaves and, therefore, the larvae, pupae and moths could provide novel sources of high-quality proteins, lipids and bioactive components.

The total protein and lipid contents of pupae comprise about $55.6 \%$ and $32.2 \%$ of dry weight, respectively [16]. Silkworm pupa protein contains high levels of essential amino acids such as valine, methionine and phenylalanine. In adults, protein and fat are also the main nutrients, although their relative proportions differ in males and females. Female moths contain higher protein and less fat than males [17]. The contents of essential amino acids in pupae and moths satisfy the requirements suggested by FAO, WHO and UNU. The proteins in pupae and moths tend to be low in sulfur-containing amino acids but

*Corresponding author: Yu-Xiao Zou, Sericultural \& Agri-Food Research Institute, Guangdong Academy of Agricultural Sciences, NO.133 Yiheng ST, Dongguanzhuang RD, Tianhe District, Guangzhou 510610, P.R. China, Tel: +8602-37227141; Fax: +86-02-87236354; E-mail: yuxiaozou@163.com

Received September 17, 2014; Accepted December 08, 2014; Published December 10, 2014

Citation: Zou YX, Liao ST, Liu F, Shen WZ, Liu J, et al (2014) Potential Medicina and Nutritional Resources from the Sericultural Industry. Med chem 4: 784-785. doi:10.4172/2161-0444.1000230

Copyright: ( 2014 Zou YX, et al. This is an open-access article distributed unde the terms of the Creative Commons Attribution License, which permits unrestricted use, distribution, and reproduction in any medium, provided the original author and source are credited. 
high in lysine and threonine, one or both of which may be deficient in cereals. Their amino acid profiles indicate that they are good sources of essential amino acids, e.g. lysine, histidine, isoleucine, aromatic amino acids, threonine and valine with a 'high protein digestibility corrected amino acid' (PDCAAS) score. Pupae and moths are rich in $n-3$ fatty acids, especially $\alpha$-linolenic acid, a precursor of eicosapentaenoic acid and of docosahexaenoic acid. DNJ was concentrated 2.7-fold by silkworms feeding on mulberry leaves [10]. Pupae and moths are also rich in other bioactive components, including selenium, vitamin $\mathrm{B} 12$, cytochrome $\mathrm{C}$, phospholipids, ecdysone, juvenile hormone and prostaglandins. These observations suggest that the pupae and moths of silkworms could provide novel sources of proteins, lipids, and an a-glucosidase inhibitor.

Silkworm pupae and moths are discarded as waste material in traditional sericultural industry. However, they are a rich source of high-quality proteins, fats, vitamins, minerals and other functional components. Further income could probably be generated from the pupae and moths if appropriate use were made of this by-product of the silk industry.

It should be emphasized that species, cultivar, origin, climate and maturity status all significantly affect the nutrient and chemical constituents of sericultural products $[7,8]$. Further research is needed to maximize the nutritional and medicinal potential of this resource.

\section{Acknowledgements}

We thank the Special Fund for Agro-scientific Research in the Public Interest, China (No.201403064), the Key Projects in the National Science \& Technology Pillar Program during the Twelfth Five-year Plan Period, China (No.2013BAD16B09) and the Foundation of the President of the Guangdong Academy of Agricultural Sciences (No. 201433) for financial support.

\section{References}

1. Tutin GT, Morus L, Tutin GT, Burges NA, Chater AO, et al. (1996) Flora Europa, Vol 1. Psilotaceae to Platanaceae, 2nd edn. Cambridge University Press: Australia.

2. Yagi M, Kouno T, Aoyagi Y, Murai H (1976) The structure of moraoline, a piperidine alkaloid from Morus species. Nippon Nougei Kagaku Kaishi 50: $571-572$.

3. Machii H, Koyama A, Yamanouchi H (2000) FAO Electronic Conference: Mulberry for animal production.
4. Ercisli S (2004) A short review of the fruit germplasm resources of Turkey. Genetic Resources and Crop Evaluation 51: 419-435.

5. Ercisli S, Orhan E (2007) Chemical composition of white (Morus alba), red (Morus rubra) and black (Morus nigra) mulberry fruits. Food Chem 103: $1380-$ 1384.

6. Hassimotto NM, Genovese MI, Lajolo FM (2008) Absorption and metabolism of cyanidin-3-glucoside and cyanidin-3-rutinoside extracted from wild mulberry (Morus nigra L.) in rats. Nutr Res 28: 198-207.

7. Isabelle M, Lee BL, Ong CN, Liu X, Huang D (2008) Peroxyl radical scavenging capacity, polyphenolics, and lipophilic antioxidant profiles of mulberry fruits cultivated in southern China. J Agric Food Chem 56: 9410-9416.

8. Song W, Wang HJ, Bucheli P, Zhang PF, Wei DZ, et al. (2009) Phytochemica profiles of different mulberry (Morus sp.) species from China. J Agric Food Chem 57: 9133-9140.

9. Kandylis K, Hadjigeorgiou I, Harizanis P (2009) The nutritive value of mulberry leaves (Morus alba) as a feed supplement for sheep. Trop Anim Health Prod 41: 17-24.

10. Asano N, Yamashita T, Yasuda K, Ikeda K, Kizu H, et al. (2001) Polyhydroxylated alkaloids isolated from mulberry trees (Morusalba L.) and silkworms (Bombyx mori L.). J Agric Food Chem 49: 4208-4213.

11. Andallu B, Suryakantham V, Lakshmi Srikanthi B, Reddy GK (2001) Effect of mulberry (Morus indica L.) therapy on plasma and erythrocyte membrane lipids in patients with type 2 diabetes. Clin Chim Acta 314: 47-53.

12. Wang CJ, Wang JM, Lin WL, Chu CY, Chou FP, et al. (2000) Protective effect of Hibiscus anthocyanins against tert-butyl hydroperoxide-induced hepatic toxicity in rats. Food Chem Toxicol 38: 411-416.

13. Peng CH, Liu LK, Chuang CM, Chyau CC, Huang CN, et al. (2011) Mulberry water extracts possess an anti-obesity effect and ability to inhibit hepatic lipogenesis and promote lipolysis. J Agric Food Chem 59: 2663-2671.

14. Zhang Y, Seeram NP, Lee R, Feng L, Heber D (2008) Isolation and identification of strawberry phenolics with antioxidant and human cancer cell antiproliferative properties. J Agric Food Chem 56: 670-675.

15. Tao W, Deqin Z, Yuhong L, Hong L, Zhanbiao L, et al. (2010) Regulation effects on abnormal glucose and lipid metabolism of TZQ-F, a new kind of Traditional Chinese Medicine. J Ethnopharmacol 128: 575-582.

16. Tomotake H, Katagiri M, Yamato M (2010) Silkworm pupae (Bombyx mori) are new sources of high quality protein and lipid. J Nutr Sci Vitaminol (Tokyo) 56 446-448.

17. Liu J, Liao ST, Zou YX, Mu LX, Shi Y, et al. (2013) Extraction Method and Process Optimization for Nutritional Active Ingredients from Male Silkworm Moths. Science of Sericulture 39: 0146 - 0151. 